\title{
Blood pressure measurement in the United Kingdom Heart Disease Prevention Project
}

\author{
R. F. Heller, G. ROSE, H. D. TUNSTAll PEDOE, AND D. G. S. CHRistie \\ From the Department of Epidemiology, St. Mary's Hospital Medical School, London
}

SUMMARY A blood pressure measurement was part of a cardiovascular screening examination of 8397 middle-aged men taking part in the intervention section of the United Kingdom Heart Disease Prevention Project. Standardised training techniques reduced observer bias to acceptable limits in four out of a total of five observers. The time of day and room temperature both made significant differences to the blood pressure measurement. High room temperatures in particular apparently had a marked effect in reducing the level of blood pressure. There were consistent and large positive associations with increasing age and overweight. The survey revealed a poor degree of blood pressure control in the community at the time of screening-only $7 \%$ of the 'hypertensive' population had their diastolic pressure controlled to below $100 \mathrm{~mm} \mathrm{Hg}$.

The Heart Disease Prevention Project is a large controlled trial in industry of the effectiveness of attempts to prevent coronary heart disease by controlling the main risk factors (World Health Organisation European Collaborative Group, 1974). The subjects were men at all socioeconomic levels aged 40 to 59 working in a wide range of industries in England and South Wales. We report here some characteristics related to blood pressure at initial examination in the intervention group. (The trial design precluded examination of the control group at this stage).

\section{Methods}

All men aged 40 to 59 employed in the factories assigned randomly to the 'intervention' section of the trial were invited for screening; 8398 accepted (an $85 \%$ response rate), and blood pressure readings were available in 8397. Height and weight were measured with shoes on and outer garments only removed. Blood pressure was measured by nurses using the London School of Hygiene sphygmomanometer (Rose et al., 1964) with the patient seated; phase 4 (muffling) was used as the diastolic endpoint. If the first systolic blood pressure was $150 \mathrm{~mm}$ $\mathrm{Hg}$ or more, a second measurement was made. If the mean of these two was $150 \mathrm{~mm} \mathrm{Hg}$ or more, the subject was asked to return on a subsequent day, when two more recordings were made. In addition, the subject completed a self-administered questionnaire which was checked by the nurse. A capillary blood sample was taken for cholesterol estimation and an electrocardiogram (limb leads only) was recorded. Room temperature was measured at the time of each examination. Five nurses took part in the examination, each of whom had undergone a standardised training in blood pressure measurement (Rose, 1965).

\section{Results}

External variables affecting the blood pressure measurement

\section{BETWEEN OBSERVER VARIATION}

Table 1 shows the mean of the first blood pressure measurements for each nurse. In order to avoid confounding factory differences and nurse differences, Table 1 also shows for each nurse a value corrected, with appropriate weighting, for the mean values of the factories where she took part. It can be seen that apart from Nurse 5, who was responsible for $7 \%$ of all the initial blood pressure recordings, the systematic differences between observers were not large. There was closer agreement between systolic than diastolic blood pressures. Systolic and diastolic differences were generally independent.

Table 1 Observer variation in blood pressure measurement

\begin{tabular}{|c|c|c|c|c|c|c|c|}
\hline \multirow{2}{*}{ Observers } & \multirow[t]{2}{*}{$n$} & \multicolumn{3}{|c|}{ Systolic BP ( $\mathrm{mm} \mathrm{Hg})$} & \multicolumn{3}{|c|}{ Diastolic BP $(\mathrm{mm} \mathrm{Hg})$} \\
\hline & & Mean & $S E$ & $\begin{array}{l}\text { Difference } \\
\text { from } \\
\text { factory } \\
\text { mean }\end{array}$ & Mean & $S E$ & $\begin{array}{l}\text { Difference } \\
\text { from } \\
\text { factory } \\
\text { mean }\end{array}$ \\
\hline $\begin{array}{l}1 \\
2 \\
3 \\
4 \\
5 \\
\text { Total }\end{array}$ & $\begin{array}{l}2134 \\
2298 \\
2235 \\
1017 \\
687 \\
8371^{*}\end{array}$ & $\begin{array}{l}141 \cdot 5 \\
140 \cdot 3 \\
139 \cdot 4 \\
140 \cdot 3 \\
132 \cdot 5 \\
139 \cdot 7\end{array}$ & $\begin{array}{l}0.41 \\
0.45 \\
0.41 \\
0.62 \\
0.73 \\
0.22\end{array}$ & $\begin{array}{r}+1.4 \\
+0.4 \\
-0.5 \\
-0.1 \\
-4.1\end{array}$ & $\begin{array}{l}82 \cdot 9 \\
85 \cdot 7 \\
83 \cdot 5 \\
87 \cdot 7 \\
78 \cdot 8 \\
84 \cdot 1\end{array}$ & $\begin{array}{l}0.28 \\
0.27 \\
0.26 \\
0.36 \\
0.48 \\
0.14\end{array}$ & $\begin{array}{r}-1.3 \\
+1.3 \\
-0.9 \\
+2.8 \\
-2.0\end{array}$ \\
\hline
\end{tabular}

*Different observer for 26 BP recordings. 


\section{REPEATED MEASUREMENTS}

For those subjects who had four blood pressure recordings (that is, those with high levels initially) Table 2 shows the mean levels at each measurement. The mean of each recording is lower than the preceding one, and this is partly due to the 'order effect' of people becoming used to having their blood pressure measured, and partly due to 'regression to the mean'. Mean pulse pressures also fall progressively. Differences between measurements on different days are greater than on the same day.

Table 2 Repeated measurements of blood pressure in 785 initially hypertensive subjects

\begin{tabular}{llllll}
\hline Visit & Recording & Systolic & \multicolumn{3}{c}{ Diastolic } \\
\hline \multirow{3}{*}{ First } & & Mean & SE & Mean & SE \\
& 1 & 177.6 & 0.52 & 100.5 & 0.46 \\
Recall & 2 & 174.0 & 0.53 & 100.0 & 0.44 \\
& 3 & 167.8 & 0.67 & 95.1 & 0.44 \\
& 4 & 164.6 & 0.66 & 94.8 & 0.44 \\
\hline
\end{tabular}

TIME OF DAY AND TEMPERATURE

Blood pressures measured in the morning were lower than those measured in the afternoon (Table 3). Higher room temperatures were strongly associated with lower blood pressures (Figure) and this association was seen in both summer and winter.

Table 3 Time of day and blood pressure

\begin{tabular}{lllllll}
\hline & $n^{*}$ & \multicolumn{2}{l}{ Systolic } & \multicolumn{3}{c}{ Diastolic } \\
\hline & & Mean & $S E$ & Mean & $S E$ \\
Morning & 3369 & $138 \cdot 5$ & $0 \cdot 34$ & $83 \cdot 2$ & $0 \cdot 21$ \\
Afternoon & 5021 & & $140 \cdot 5$ & $0 \cdot 29$ & 84.6 & $0 \cdot 18$ \\
\hline
\end{tabular}

*Time of day not recorded for seven observations.

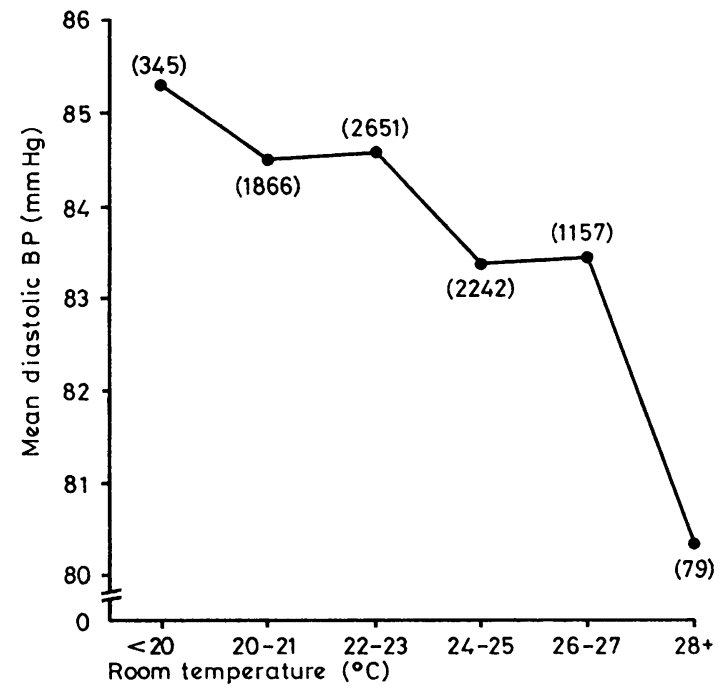

Figure Room temperatures and blood pressure.
The influence of some personal characteristics on blood pressure

\section{AGE AND BLOOD PRESSURE}

Blood pressure increased with age (Table 4), and the trend was steeper for systolic than diastolic. Thus, the difference between systolic and diastolic readings (pulse pressure) increased by $14 \%$ from the age group 40-44 to the age group 55-59, while the systolic pressure increased by $7 \%$ and the diastolic by $3 \%$ between the same age groups.

Table 4 Age and blood pressure

\begin{tabular}{llllll}
\hline Age group & & & & & \\
\hline (years) & $n$ & Systolic & & Diastolic \\
& & Mean & SD & Mean & SD \\
$40-44$ & 1984 & $135 \cdot 1$ & $17 \cdot 3$ & $82 \cdot 4$ & $12 \cdot 1$ \\
$45-49$ & 2286 & $138 \cdot 5$ & $19 \cdot 3$ & $84 \cdot 2$ & $13 \cdot 1$ \\
$50-54$ & 2298 & $140 \cdot 8$ & $20 \cdot 6$ & $84 \cdot 6$ & $12 \cdot 7$ \\
$55-59$ & 1829 & $144 \cdot 9$ & $21 \cdot 6$ & $84 \cdot 9$ & $13 \cdot 2$ \\
All ages & 8397 & $139 \cdot 7$ & $20 \cdot 0$ & $84 \cdot 1$ & $12 \cdot 8$ \\
\hline
\end{tabular}

\section{OVERWEIGHT AND BLOOD PRESSURE}

Table 5 shows the relationship between blood pressure and overweight. The latter is expressed as relative weight, using age-specific mean weights for given height in the Whitehall study (Reid et al., 1974) as the reference standard. There is a strong and consistent trend, similar for both systolic and diastolic pressures. Towards the obese end of the range, some of this apparent effect may be due to the exaggeration in blood pressure readings when the sphygmomanometer cuff does not fully encircle the arm; a standard Accoson cuff was used throughout; the length of the inflatable portion was $23 \mathrm{~cm}$.

Table 5 Overweight and blood pressure

\begin{tabular}{crllll}
\hline Relative weight & $n^{*}$ & Systolic & \multicolumn{3}{c}{ Diastolic } \\
\hline & & Mean & $S D$ & Mean & $S D$ \\
$\geqslant 1.25$ & 344 & 150.0 & 20.2 & $91 \cdot 7$ & 13.1 \\
$1.15-1.24$ & 769 & 144.8 & 19.9 & 88.9 & 12.4 \\
$1.05-1.14$ & 2039 & 142.4 & 19.9 & 86.9 & 12.7 \\
$0.95-1.04$ & 3028 & 139.1 & 19.6 & 83.4 & 12.1 \\
$0.85-0.94$ & 1582 & 135.6 & 19.8 & 80.2 & 12.2 \\
$<0.85$ & 628 & 132.7 & 18.4 & 77.6 & 12.0 \\
\hline
\end{tabular}

${ }^{*}$ Height/weight not available for seven subjects.

\section{Prior knowledge of hypertension}

In the self-administered questionnaire, subjects were asked whether they had previously been told that they had a raised blood pressure and whether they had been given treatment for it. As Table 6 shows, the higher the screening blood pressure, the more likely was the subject to have prior knowledge of his hypertension. There was little difference in this respect between systolic and diastolic levels.

With a definition of 'hypertension' which included a screening diastolic pressure of $100 \mathrm{~mm} \mathrm{Hg}$ or more $(n=939)$, and adding those with lower 
levels but who were receiving hypertensive treatment $(n=71)$, it appears that only $7 \%(71 / 1010)$ of the hypertensive subjects had their blood pressure 'controlled' (that is, diastolic BP below $100 \mathrm{~mm} \mathrm{Hg}$ ). Using a diastolic pressure of $110 \mathrm{~mm} \mathrm{Hg}$ as the cut-off point for defining hypertension, $29 \%$ $(110 / 379)$ of the hypertensive population were adequately controlled to below $110 \mathrm{~mm} \mathrm{Hg}$. This compares with the finding that of the 150 subjects currently receiving treatment for hypertension, $47 \%$ had a screening diastolic blood pressure level below $100 \mathrm{~mm} \mathrm{Hg}$ and $73 \%$ below $110 \mathrm{~mm} \mathrm{Hg}$. Treatment for blood pressure was still being continued in only about half of those who had ever had such treatment. Surprisingly, $68 \%$ of the subjects who had previously been told that they had raised blood pressure now had a diastolic level below $100 \mathrm{~mm} \mathrm{Hg}$, and in only $12 \%$ could current treatment account for this apparent control of previous hypertension.

Table 6 Knowledge and treatment of hypertension according to blood pressure level

\begin{tabular}{|c|c|c|c|c|}
\hline $\begin{array}{l}\text { Systolic quintile } \\
\text { (range in mm } \mathrm{Hg}) \\
1(<123) \\
2(123-133) \\
3(133-143) \\
4(143-154) \\
5(\geqslant 154)\end{array}$ & $\begin{array}{l}n \\
1679 \\
1679 \\
1679 \\
1678 \\
1679\end{array}$ & $\begin{array}{l}\text { Ever told } \\
\text { BP raised } \\
2 \cdot 7 \% \quad(45) \\
3 \cdot 5 \% \quad(59) \\
5.3 \% \text { (89) } \\
7.2 \% \text { (120) } \\
16.9 \%(284)\end{array}$ & $\begin{array}{l}\text { Ever given } \\
B P \text { treatment } \\
1 \cdot 0 \% \quad(17) \\
1 \cdot 2 \% \quad(20) \\
2 \cdot 5 \% \quad(42) \\
3 \cdot 2 \% \quad(54) \\
9 \cdot 8 \%(165)\end{array}$ & $\begin{array}{l}\text { Now on } B P \\
\text { treatment } \\
0.4 \%(6) \\
0.6 \%(10) \\
1.2 \%(20) \\
1.0 \%(16) \\
5.8 \%(98)\end{array}$ \\
\hline \multicolumn{5}{|l|}{$\begin{array}{l}\text { Diastolic quintile } \\
\text { (range in } \mathrm{mm} \mathbf{H g} \text { ) }\end{array}$} \\
\hline $\begin{array}{l}1(<73) \\
2(73-80) \\
3(80-86) \\
4(86-94) \\
5(\geqslant 94)\end{array}$ & $\begin{array}{l}1679 \\
1679 \\
1679 \\
1678 \\
1679\end{array}$ & $\begin{array}{r}3.0 \% \quad(50) \\
4.6 \% \quad(77) \\
5.2 \% \quad(87) \\
7.1 \%(119) \\
15.7 \%(264)\end{array}$ & $\begin{array}{l}1 \cdot 1 \% \quad(18) \\
1 \cdot 8 \% \quad(30) \\
2 \cdot 4 \% \quad(41) \\
3 \cdot 2 \% \quad(54) \\
9 \cdot 2 \% \quad(155)\end{array}$ & $\begin{array}{l}0.4 \%(6) \\
0.9 \%(15) \\
0.6 \%(11) \\
1.5 \%(26) \\
5.5 \%(92)\end{array}$ \\
\hline Total & 8394* & $7 \cdot 1 \%$ (597) & $3.6 \%(298)$ & $1 \cdot 8 \%(150)$ \\
\hline
\end{tabular}

Table 7 Blood pressure change at second or third anniversary in initially hypertensive men

\begin{tabular}{lllll}
\hline & & $\begin{array}{l}\text { Mean Systolic BP mm Hg } \\
\text { Initial } \\
\text { screening }\end{array}$ & Anniversary & $\begin{array}{l}\text { \% change } \\
\text { in two or } \\
\text { three } \\
\text { years }\end{array}$ \\
\hline On treatment & 227 & 184.9 & 163.5 & $-11.6 \%$ \\
Not on treatment & 323 & 175.7 & 163.5 & $-6.9 \%$ \\
Total & 550 & 179.5 & 163.5 & $-8.9 \%$ \\
\hline
\end{tabular}

\section{Results of treatment}

Men whose four systolic readings averaged $160 \mathrm{~mm} \mathrm{Hg}$ or more but who were not currently receiving treatment were referred either to their general practitioners or to the factory doctors, who then decided on the need for treatment. These men were invited for re-examination at either the second or the third anniversary of their original screening; 550 men attended and $227(41 \%)$ were under treatment for hypertension at this time. Table 7 shows that the initial pressures of the treated group were higher than in those who were not treated, but by the time of the second or third anniversary, the two groups had the same blood pressure levels.

\section{Discussion}

The results of this large study of the blood pressures of middle-aged working men in all socioeconomic groups in various parts of England and Wales are particularly relevant to epidemiology, screening policy, and clinical practice. In the first place, standardised training techniques have reduced observer bias to acceptable levels in all but one of our five observers. The need for care and vigilance on this point is illustrated by the example of our fifth nurse, who joined the team later and turned out to be a 'low reader' in spite of special training. Overall, the quality of the data is good, and these results probably provide the best available guide to blood pressure levels of a representative cross-section of middle-aged men in Britain.

The fact that subsequent measurements tend to be lower than the first screening blood pressure level is well known, and it emphasises the need to use more than one recording to characterise baseline blood pressure when treatment is being considered. It also appears that a repeat measurement on a subsequent day may show a greater difference than repeating the observation at the same visit. The time of day appears to have a significant effect on blood pressure levels but the differences in this study are not large enough to have much practical importance. Other population surveys (Wilhelmsen et al., 1973) have found a greater difference, in the same direction of higher afternoon blood pressures, although a recent study using continuous intraarterial recording (Millar-Craig et al., 1978) showed a progressive fall in blood pressure from a midmorning high.

The effect of room temperature on blood pressure was marked, and may explain the previous report of a seasonal influence on blood pressure levels (Rose, 1961). In the present study, standardisation for room temperature largely removed the seasonal effect. This gives rise to the thought that screening, usually performed at equable room temperature, may mask real blood pressure differences associated with different temperatures at home. It also affects the interpretation of apparent differences in mean pressure between populations and other groups examined at different temperatures, thereby raising a further major difficulty in standardising blood pressure studies.

The well-known influence on blood pressure of various personal characteristics, such as age and overweight, is confirmed by this study. Although 
age affects the systolic level to a relatively greater extent than the diastolic level, the converse is true with overweight. This suggests that the mechanism of such influences may be different. Some of the weight effect may, of course, be due to measurement artifact.

This study took place between 1971 and 1973, and the extent of detected hypertension found to be uncontrolled at that time may be less today. Nevertheless, the fact that only $29 \%$ of those with hypertension (defined as a casual diastolic reading of $110 \mathrm{~mm} \mathrm{Hg}$ or more) were controlled to below that level, illustrates the poor state of hypertension control in the community at the time of the study. Once people were started on treatment the control appeared to be quite good; the main problem seems to be the large number of men of this age with high blood pressure levels who were not being treated.

The mean blood pressure of all the hypertensive subjects fell by $9 \%$ after two or three years, but it can be seen that there was a fall of $7 \%$ even in those not treated. The reduction in blood pressure on treatment may therefore be ascribed partly to the order effect of repeated measurements, partly to 'regression to the mean', and only partly to any effect of treatment. This emphasises the importance of including an adequate control group in any assessment of blood pressure response to treatment.
We thank the nurses who performed the screening examinations and the occupational physicians and their staff for help throughout the study.

Reprints from Professor Geoffrey Rose, London School of Hygiene and Tropical Medicine, Keppel Street, London WC1E 7HT.

\section{References}

Millar-Craig, M. W., Bishop, C. N., and Raftery, E. B. (1978). Circadian variation of blood pressure. Lancet, 1, 795-797.

Reid, D. D., Brett, G. Z., Hamilton, P. J. S., Jarrett, R. J., Keen, H., and Rose, G. (1974). Cardiorespiratory disease and diabetes among middle-aged male civil servants. Lancet, 1, 469-473.

Rose, G. (1961). Seasonal variation in blood pressure in man. Nature, 189, 235.

Rose, G. A., Holland, W. W., and Crowley, E. A. (1964). A sphygmomanometer for epidemiologists. Lancet, 1, 296-300.

Rose, G. (1965). Standardisation of observers in blood pressure measurement. Lancet, 1, 673-674.

Wilhelmsen, L., Berglund, G., and Werkö, L. (1973). Prevalence and management of hypertension in a general population sample of Swedish men. Preventive Medicine, 2, 57-66.

World Health Organisation European Collaborative Group (1974). An international controlled trial in the multifactorial prevention of coronary heart disease. International Journal of Epidemiology, 3, 219-224. 